\title{
Classificação de lotes comerciais de feijão por meio da claridade do tegumento dos grãos
}

\author{
Classify the common bean commerciais lots by the clarity of the grain tegument
}

\author{
Nerinéia Dalfollo Ribeiro" ${ }^{\text {* }}$ Lindolfo Storck ${ }^{\mathrm{I}}$ Nerison Luís Poersch ${ }^{\mathrm{II}}$
}

\begin{abstract}
- NOTA -
RESUMO

A avaliação da claridade do tegumento dos grãos de feijão (valor de " $L$ ”) é uma medida recente e ainda pouco utilizada no melhoramento. Por isso, o objetivo deste trabalho foi determinar se é possível classificar genótipos de feijão pelo valor de " $L$ ", dentro de mesmo grupo comercial, e avaliar o

The clarity of grain tegument is associated with the commercial value of common bean cultivar. Values between 0.50 and 3.33 were significative different by Tukey test. The clarity of grains tegument (' $L$ ' value) can be used to classify common bean lots of same commercial group. Two repetitions are sufficient to evaluate common bean grains tegument colors, with $90 \%$ accuracy of the real value and high experimental precision.
\end{abstract} número de repetições necessárias. Dezenove ensaios foram conduzidos em Santa Maria, RS, durante os anos de 1998/ 1999 a 2005/2006, com número variável de genótipos. A coloração do tegumento dos grãos foi quantificada com colorímetro em grãos com $13 \%$ de umidade, imediatamente após a colheita. Considerando que a claridade dos grãos é associada ao valor comercial da cultivar, apenas os valores de " $L$ " foram submetidos às análises. Valores entre 0,50 e 3,33 para o valor de " $L$ " foram significativamente diferentes pelo teste de Tukey. A claridade do tegumento dos grãos pode ser utilizada para classificar lotes de feijão de um mesmo grupo comercial. Duas repetições são suficientes para a avaliação da coloração do tegumento dos grãos em feijão, com $90 \%$ de exatidão no prognóstico de seu valor real, e com alta precisão experimental.

Palavras-chave: Phaseolus vulgaris L., precisão experimental, repetibilidade, seleção, cor dos grãos.

\section{ABSTRACT}

The estimation of the common bean grain clarity (' $L$ 'value) is a new measure and it is not much used in the breeding programs. The objective of this research was to determine the possibility to classifying common bean genotypes for the ' $L$ ' value, within the same commercial group and to evaluate how many repetitions are necessary. Nineteen experiments were conducted in Santa Maria, in Rio Grande do Sul State, Brazil, from 1998/1999 to 2005/2006 years. The grain tegument colors were determined with $13 \%$ moisture.
Key words: Phaseolus vulgaris L., experimental precision, repeatability, selection, colors of grains.

O feijão (Phaseolus vulgaris L.) apresenta grande diversidade de cores. O tipo carioca - grãos bege com estrias marrons - é o mais consumido no Brasil e os grãos de tegumento preto e de outras cores são de utilização menos expressiva e regionalizada. A claridade dos grãos está estreitamente associada à preferência para o consumo e ao valor comercial do produto, sendo um parâmetro de interesse nos programas de melhoramento genético.

A coloração do tegumento dos grãos pode ser medida com colorímetro, que possibilita a identificação do espectro de cores. Essa informação é obtida em um sistema tridimensional, sendo que o eixo vertical, "L", refere-se à cor da amostra do preto ao branco; o eixo "a”, da cor verde ao vermelho; e o eixo "b”, da cor azul ao amarelo (BRACKMANN et al., 2002).

O valor de "L" é uma das informações relevantes para o feijão, pois está vinculado à claridade dos grãos. Em grãos do tipo carioca, a maior claridade

'Departamento de Fitotecnia, Centro de Ciências Rurais (CCR), Universidade Federal de Santa Maria (UFSM), 97105-900, Santa Maria, RS, Brasil. E-mail: neiadr@smail.ufsm.br.*Autor para correspondência.

"Curso de Agronomia, UFSM, Santa Maria, RS, Brasil. 
do tegumento dos grãos é associada com grãos recémcolhidos e de rápido cozimento. Por isso, cultivares com "L" superior a 55 têm maior valor no mercado. No entanto, a menor claridade é desejável pelo consumidor e implica maior aceitação para grãos pretos, porque cultivares com "L" superior a 22 possuem grande percentagem de grãos arroxeados, o que é relacionado à qualidade inferior e à necessidade de maior tempo para o cozimento (RIBEIRO et al., 2003). No entanto, essas relações são feitas de forma empírica e subjetiva.

Subsídios para o planejamento de experimentos mais eficientes para a avaliação do rendimento de grãos de feijão podem ser obtidos nos estudos do tamanho da parcela (ESTEFANEL et al., 1993) e da amostra (ESTEFANEL et al., 1996), do uso de bordaduras (MARQUES JÚNIOR et al., 1997), do número de experimentos necessários para a comparação de cultivares (CARGNELUTTI FILHO et al., 2006) e do efeito da densidade de plantas sobre a precisão experimental (RIBEIRO et al., 2004). Entretanto, não há informações sobre a avaliação da coloração do tegumento dos grãos de feijão que permitam estabelecer a precisão das medidas e sequer quantas repetições são necessárias. Até o presente, não se tem conhecimento de estratégias de seleção de germoplasma vinculada à claridade de grãos que possam auxiliar o lançamento de cultivares superiores no mercado nacional. Essas informações auxiliariam os pesquisadores na aplicação adequada dos testes de hipóteses e no planejamento dos ensaios. Assim, foram objetivos deste trabalho: determinar a possibilidade de classificação de genótipos de feijão pela claridade do tegumento de grãos, dentro de mesmo grupo comercial, bem como avaliar a quantidade de medições necessárias à predição desse caráter.

Dezenove ensaios de competição de linhagens avançadas e cultivares de feijão foram conduzidos, nos anos de 1998/1999 a 2005/2006 em duas épocas de cultivo (safra e safrinha, Tabela 1), em área experimental da Universidade Federal de Santa Maria, Santa Maria, RS, localizada na região fisiográfica da depressão central do Estado do Rio Grande do Sul, entre as coordenadas geográficas de $29^{\circ} 45^{\prime}$ latitude sul, $53^{\circ} 42^{\prime}$ longitude a oeste de Greenwich, e a uma altitude de $95 \mathrm{~m}$.

O delineamento experimental de blocos ao acaso, com três repetições, foi utilizado nos ensaios de Valor de Cultivo e Uso (VCU) e de cultivares registradas para o cultivo no Estado do Rio Grande do Sul, com diferentes números de genótipos em cada ano (Tabela 1). Para os ensaios 18 e 19, foram utilizadas quatro repetições. As parcelas foram compostas de quatro fileiras de $4 \mathrm{~m}$ de comprimento, espaçadas de 0,50m, sendo o preparo do solo, a adubação, a semeadura e o

Tabela 1 - Caracterização dos ensaios de cultivares e de valor de cultivo e uso (VCU) de feijão, executados em Santa Maria, RS, média, amplitude (entre médias de genótipos) e quadrado médio do erro (QMe) da coloração do tegumento dos grãos de feijão (valor de L) obtida logo após a colheita.

\begin{tabular}{|c|c|c|c|c|c|c|}
\hline Ensaio & Ano - época & Tipo & Número de genótipos & Média & Amplitude & QMe \\
\hline 1 & 2000/00 - Safra & Cultivares & 16 & $35,52 *$ & 39,42 & 0,316 \\
\hline 2 & 2001 - Safrinha & Cultivares & 16 & $35,66 *$ & 39,05 & 0,184 \\
\hline 3 & 2001/02 - Safra & Cultivares & 19 & $34,82 *$ & 38,06 & 0,922 \\
\hline 4 & 2002 - Safrinha & Cultivares & 19 & $34,02 *$ & 38,78 & 0,513 \\
\hline 5 & 2002/03 - Safra & Cultivares & 19 & $31,07 *$ & 32,96 & 0,453 \\
\hline 6 & 2003 - Safrinha & Cultivares & 19 & $31,61 *$ & 34,33 & 1,161 \\
\hline 7 & 2003/04 - Safra & Cultivares & 19 & $33,17 *$ & 37,77 & 0,246 \\
\hline 8 & 2004 - Safrinha & Cultivares & 20 & $35,48 *$ & 43,69 & 0,298 \\
\hline 9 & 2004/05 - Safra & Cultivares & 18 & $31,95 *$ & 35,83 & 0,321 \\
\hline 10 & 2005/06 - Safra & Cultivares & 21 & $30,35 *$ & 35,37 & 0,280 \\
\hline 11 & 1998/99 - Safra & VCU & 20 & $25,27 *$ & 38,22 & 0,338 \\
\hline 12 & 1999/00 - Safra & VCU & 20 & $25,66^{*}$ & 41,24 & 0,103 \\
\hline 13 & 2000/01 - Safra & VCU - Preto & 24 & $22,45^{*}$ & 3,81 & 0,025 \\
\hline 14 & 2001/02 -Safra & VCU - Preto & 18 & $21,40 *$ & 4,64 & 0,088 \\
\hline 15 & 2001/02 - Safra & VCU - Carioca & 14 & $52,51 *$ & 6,63 & 0,227 \\
\hline 16 & 2003/04 - Safra & VCU - Preto & 26 & $21,94 *$ & 16,12 & 0,101 \\
\hline 17 & 2003/04 - Safra & VCU - Carioca & 16 & $56,96 *$ & 10,06 & 0,354 \\
\hline 18 & 2004/05 - Safra & VCU & 16 & $33,99 *$ & 39,27 & 0,288 \\
\hline 19 & 2005/06 - Safra & VCU & 16 & $31,36^{*}$ & 34,79 & 0,208 \\
\hline
\end{tabular}

* Diferença entre genótipos significativa pelo teste F em nível de 1\% de probabilidade de erro.

Ciência Rural, v.38, n.7, out, 2008. 
controle de insetos e de plantas daninhas realizados de forma convencional.

Amostras de $100 \mathrm{~g}$ de grãos, com 13\% de umidade, foram selecionadas e dispostas em placas de "Petri" de 22cm de diâmetro e $3 \mathrm{~cm}$ de altura, de modo que os grãos cobrissem completamente o fundo do recipiente, conforme proposto por BRACKMANN et al. (2002). A quantificação do valor de “L” foi realizada com colorímetro, marca Minolta, modelo CR-310, sempre durante o dia, no interior de uma sala iluminada com lâmpadas fluorescentes. O sensor do aparelho foi colocado sobre a amostra de forma que o feixe de luz incidisse, na sua totalidade, sob as amostras.

A média geral e as médias dos genótipos foram estimadas. A análise da variância foi realizada para o teste de hipótese referente ao efeito de genótipos, estimando-se o coeficiente de variação experimental (CVe) e o genético (CVg). Para as estimativas de CVe e CVg, em percentagem da média geral do ensaio ( $\mathrm{m})$, foram usados o quadrado médio do erro (QMe), o quadrado médio de genótipos (QMg) e o número de repetições (J), por meio das expressões: $\mathrm{CVe}=100 \sqrt{ }\left(\mathrm{QMe} / \mathrm{h}^{2}\right)$ e $C V g=100 \sqrt{ }\left[(\mathrm{QMg}-\mathrm{QMe}) / \mathrm{Jm}^{2}\right]$.

As avaliações em cada bloco foram consideradas como medições realizadas no mesmo indivíduo (genótipo) e estimaram-se os coeficientes de repetibilidade (r̂), em cada ensaio, pelo método da análise de variância, utilizando-se: $\mathrm{r}=\mathrm{Vgm} /(\mathrm{Vgm}+\mathrm{QMe})$, em que Vgm =(QMg-QMe)/J = variância genética média. O número $\left(\mathrm{n}_{0}\right)$ mínimo de repetições necessário para predizer o valor real dos indivíduos (genótipos), com base no coeficiente de determinação $\left(R^{2}\right)$ préestabelecido em 0,90 foi obtido por: $\mathrm{n}_{0}=0,9 *(1-) /(\hat{\mathrm{r}} /$ 10) (CRUZ \& REGAZZI, 1997).

O valor da estatística diferença mínima significativa entre os genótipos foi calculado pelo teste de Tukey (DT) a 1\% de probabilidade de erro, sendo

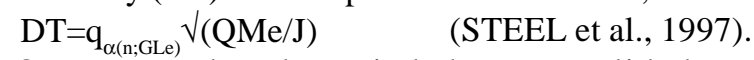
Os testes de aleatoriedade, normalidade e homocedasticidade do erro foram empregados para verificar o atendimento das pressuposições do modelo (STEEL et al., 1997; SPRENT \& SMEETON, 2007).

Em 100\% dos ensaios foi observado efeito significativo para genótipo (Tabela 1), tornando possível a identificação de germoplasma de feijão pela claridade do tegumento dos grãos (valor de “L”). Além disso, foi possível diferenciar genótipos do mesmo grupo (preto ou carioca) pelo valor de “L”, pois diferenças significativas foram observadas nos ensaios 13 (grãos pretos) e 17 (grãos carioca).

O coeficiente de variação experimental (CVe) variou de $0,7 \%$ a $3,4 \%$ (Tabela 2 ), indicando reduzida contribuição do ambiente sob esse caráter. Por sua vez, o coeficiente de variação genético ( $\mathrm{CVg}$ ) foi relativamente alto (maior que $46,8 \%$ ) para a maioria dos ensaios, com exceção dos ensaios 13 a 17, pois foram executados com genótipos exclusivamente do mesmo grupo (preto ou carioca). Pela avaliação de cultivares de feijão de diferentes grupos, também foi observado CVg elevado. Isso revela que a determinação do valor de "L" é uma medida que pode ser útil para um programa de melhoramento, pois apresenta grande efeito genético.

Diferenças entre 0,50 (ensaio 13) e 3,33 (ensaio 6) na claridade do tegumento dos grãos foram significativamente diferentes pelo teste de Tukey (DT, Tabela 2). Amédia das DT foi de 1,65, valor extremamente baixo quando se considera os valores médios de L para o grupo de genótipos com grãos pretos (média de L igual a 21,40, no ensaio 14) e do tipo carioca (média de L igual a 52,51, no ensaio 15), no mesmo ano (Tabela 1). Sendo assim, é possível classificar lotes de feijão pela claridade do tegumento dos grãos (valor de L) em determinado grupo comercial, com pequenas diferenças e com grande precisão ou boa repetibilidade.

As magnitudes das estimativas do coeficiente de repetibilidade ( ) oscilaram entre 0,937 e 1,000 (Tabela 2). Foi possível identificar genótipos com cores diferentes, com precisão de $90 \%$, para um máximo de duas repetições, o que pressupõe diminuta influência do ambiente sobre esse caráter.

Em todos os ensaios, o erro experimental revelou distribuição aleatória entre as unidades experimentais e as variâncias entre os genótipos não foram heterogêneas. Esses dois pressupostos parecem não limitar os testes de hipótese para o caráter. Em 50\% dos ensaios não foi constatado o pressuposto da distribuição normal dos erros, fundamental para a validação dos testes de hipótese. Neste estudo, não há indicação de transformação adequada aos dados e a análise não paramétrica é inapropriada aos objetivos. No entanto, considerando que a precisão é elevada, a falta de normalidade não deve comprometer a constituição dos lotes.

Considerando que a avaliação da coloração do tegumento dos grãos não requer a destruição do grão, além de ser rápida e de execução simples, sugerese que seja usada nos programas de melhoramento, pois apenas duas repetições são suficientes para a identificação de diferenças entre os genótipos, com alta precisão experimental. Além disso, CARGNELUTTI et al. (2006) verificaram que apenas um experimento é suficiente para selecionar linhagens de feijão pela coloração do tegumento dos grãos, com 99\% de 
Tabela 2 - Coeficiente de variação experimental (CVe) e genético (CVg), adequação dos erros aos pressupostos da normalidade (Nor), aleatoriedade (Aleat) e homogeneidade das variâncias entre genótipos (Hom), valor da diferença mínima significativa pelo teste de Tukey (DT) e amplitude dividida pela DT (HD), coeficiente de repetibilidade ( $\hat{\mathrm{r}}$ ) e número de repetições $\left(\mathrm{n}_{0}\right)$ para diferentes ensaios de avaliação da coloração do tegumento dos grãos de feijão logo após a colheita.

\begin{tabular}{|c|c|c|c|c|c|c|c|c|c|}
\hline Ensaio & CVe & CVg & Nor & Aleat & Hom & DT & HD & $\hat{\mathrm{r}}$ & $\mathrm{n}_{\mathrm{o}}$ \\
\hline 1 & 1,6 & 48,5 & Sim & Sim & Sim & 1,71 & 23,1 & 0,999 & 0,0 \\
\hline 2 & 1,2 & 49,5 & Não & Sim & Sim & 1,31 & 29,9 & 0,999 & 0,0 \\
\hline 3 & 2,8 & 51,9 & Não & Sim & Sim & 2,97 & 12,8 & 0,997 & 0,0 \\
\hline 4 & 2,1 & 52,0 & Não & Sim & Sim & 2,22 & 17,5 & 0,998 & 0,0 \\
\hline 5 & 2,2 & 48,5 & Não & Sim & Sim & 2,08 & 15,8 & 0,998 & 0,0 \\
\hline 6 & 3,4 & 48,6 & Sim & Sim & Sim & 3,33 & 10,3 & 0,995 & 0,0 \\
\hline 7 & 1,5 & 52,2 & Sim & Sim & Sim & 1,53 & 24,6 & 0,999 & 0,0 \\
\hline 8 & 1,5 & 52,7 & Sim & Sim & Sim & 1,70 & 25,7 & 0,999 & 0,0 \\
\hline 9 & 1,8 & 47,1 & Não & Sim & Sim & 1,75 & 20,5 & 0,999 & 0,0 \\
\hline 10 & 1,7 & 47,1 & Sim & Sim & Sim & 1,65 & 21,4 & 0,999 & 0,0 \\
\hline 11 & 2,3 & 51,4 & Não & Sim & Sim & 1,81 & 21,2 & 0,998 & 0,0 \\
\hline 12 & 1,2 & 57,0 & Não & Sim & Sim & 1,00 & 41,2 & 1,000 & 0,0 \\
\hline 13 & 0,7 & 4,3 & Sim & Sim & Sim & 0,50 & 7,7 & 0,974 & 0,2 \\
\hline 14 & 1,4 & 5,4 & Sim & Sim & Sim & 0,92 & 5,1 & 0,937 & 0,6 \\
\hline 15 & 0,9 & 4,1 & Sim & Sim & Sim & 1,44 & 4,6 & 0,953 & 0,4 \\
\hline 16 & 1,4 & 15,5 & Sim & Sim & Sim & 1,01 & 15,9 & 0,991 & 0,0 \\
\hline 17 & 1,0 & 4,7 & Sim & Sim & Sim & 1,81 & 5,6 & 0,953 & 0,4 \\
\hline 18 & 1,6 & 50,2 & Não & Sim & Sim & 1,38 & 28,5 & 0,999 & 0,0 \\
\hline 19 & 1,5 & 46,8 & Não & Sim & Sim & 1,17 & 29,7 & 0,999 & 0,0 \\
\hline
\end{tabular}

exatidão. Sendo assim, a identificação de cultivares de feijão com claridade adequada à preferência para o consumo, em cada grupo comercial, poderá resultar em maior aceitação e valorização pelo mercado.

\section{AGRADECIMENTOS}

Ao Conselho Nacional de Desenvolvimento Científico e Tecnológico (CNPq), pelas bolsas concedidas.

\section{REFERÊNCIAS}

BRACKMANN, A. et al. Conservação de três genótipos de feijão (Phaseolus vulgaris L.) do grupo carioca em armazenamento refrigerado e em atmosfera controlada. Ciência Rural, Santa Maria, v.32, n.6, p.911-915, 2002.

CARGNELUTTI FILHO, A. et al. Número necessário de experimentos para a comparação de cultivares de feijão. Ciência Rural, Santa Maria, v.36, n.6, p.1701-1709, 2006.

CRUZ, C.D.; REGAZZI, A.J. Modelos biométricos aplicados ao melhoramento genético. 2.ed. Viçosa: UFV, 1997. 390p.
ESTEFANEL, V. et al. Determinação do tamanho ideal da parcela para estimar o rendimento de grãos da cultura do feijoeiro. Ciência Rural, Santa Maria, v.23, n.1, p.97-98, 1993.

ESTEFANEL, V. et al. Tamanho da amostra para avaliação de componentes do rendimento na cultura do feijoeiro. Ciência Rural, Santa Maria, v.26, n.3, p.367-370, 1996.

MARQUES JÚNIOR, O.G. et al. Efeito de parcelas adjacentes na avaliação de alguns caracteres em cultivares de feijão. Bragantia, Campinas, v.56, n.1, p.199-206, 1997.

RIBEIRO, N.D. et al. Precisão experimental na avaliação de cultivares de feijão de diferentes hábitos de crescimento. Ciência Rural, Santa Maria, v.34, n.5, p.1371-1377, 2004.

RIBEIRO, N.D. et al. Progresso genético em caracteres agronômicos no melhoramento do feijoeiro. Ciência Rural, Santa Maria, v.33, n.4, p.629-633, 2003.

SPRENT, P.; SMEETON, N.C. Applied nonparametric statistical methods. 4.ed. Boca Raton: Chapman \& Hall, 2007. 530p.

STEEL, R.G.D. et al. Principles and procedures of statistics: a biometrical approach. 3.ed. New York: McGraw Hill Book, 1997. 666p. 